\title{
ПРОБЛЕМЫ ПРАВОПРИМЕНЕНИЯ
}

\section{СУБСИДИИ И ГРАНТЫ - ПРАВОВЫЕ ИНСТРУМЕНТЫ РАЗВИТИЯ ЭКОНОМИКИ*}

\begin{abstract}
АННОТАЦИЯ
В современных экономических условиях бюджетные субсидии являются ключевым инструментом осуществления социальной и экономической политики государства.

На основе анализа российского и зарубежного законодательства, регулирующего порядок предоставления субсидий, авторами предпринята попытка создания универсальной правовой конструкции субсидий, подлежащей адаптации к условиям, целям назначения и предполагаемым результатам субсидирования.
\end{abstract}

КЛЮЧЕВЫЕ СЛОВА: субсидия; грант; бюджет; утилизационный сбор; концессионные соглашения; государственные закупки; ответственность; ущерб.

\begin{abstract}
In modern economic conditions, budget subsidies are a key tool for implementing the social and economic policy of the state.

Based on the analysis of Russian and foreign legislation governing the procedure for granting subsidies, the authors made an attempt to create a universal legal structure of subsidies, subject to adaptation to the conditions, purposes of appointment and the expected results of subsidies.
\end{abstract}

KEY WORDS: subsidy; grant; budget; utilization fee; concession agreements; public procurement; liability; damage.

В складывающихся экономических условиях резко повышается роль государственного финансирования затрат хозяйственных организаций, научно-исследовательских учреждений, индивидуальных предпринимателей на цели, предполагающие определенный публичный интерес, - реализацию результатов НИР, инвестиции в перспективные производства, «расшивку узких мест» для развития экономики.

Получение бюджетной системой новых функций остро ставит вопросы правового совершенствования осуществления бюджетных расходов. Привычное сметно-бюджетное финансирование заменяется новыми инструментами субсидиями, субвенциями, грантами, но эта замена в юридическом отношении несколько отстает от потребностей практики и создает ряд проблем, требующих решения в целях создания современного механизма осуществления государственных (публичных) расходов и его увязки с режимом самофинансирования хозяйствующих субъектов, в том числе некоммерческих организаций. В этом направлении должны быть преодолены реликты безвозвратного финансирования из бюджета, равно как и поверхностной отчетности о произведенных расходах и достигнутых результатах. Субсидии, субвенции, гранты выступают как юридические средства обеспечения двусторонности бюджетных взаимоотношений, привнесения ответственности за использование

\footnotetext{
* Статья подготовлена в рамках поддержанного Российским фондом фундаментальных исследований научного проекта № 18-29-15035-мк «Сравнительно-правовое исследование механизма назначения, выдачи и использования грантов в целях финансирования научно-исследовательских, опытно-конструкторских и технологических работ».
} 
бюджетных средств, а главное - достижения экономического эффекта как для субъекта-исполнителя, так и для всего общества.

Законодателем предпринимаются энергичные попытки по развитию и углублению субсидирования как главного способа осуществления инвестиций и оказания хозяйствующим субъектам экономической поддержки. В Бюджетном кодексе РФ стремительно увеличивается количество и объем статей, закрепляющих порядок предоставления субсидий по разным направлениям экономической деятельности. В настоящий момент порядок предоставления субсидий определен в ст. 78-78³ БК РФ, на основании которых сформирован значительный массив подзаконных нормативных правовых актов федерального и регионального уровня.

Субсидии, количество которых в последнее время резко возросло, в правовом отношении должны строиться с учетом международных правовых актов, применение которых зачастую не полностью соответствует механизму государственной финансовой поддержки. Прежде всего, это связано с тем, что международными актами предусматривается достаточно широкая трактовка понятия «субсидия», в том числе понятия «запрещенная субсидия». В частности, в соответствии с Соглашением по субсидиям и компенсационным мерам (заключено в Марракеше 15 апреля 1994 г.) субсидией, противоречащей правилам ВТО (Всемирная торговая организация), признается не только прямое финансирование экспортеров, но и создание благоприятных для покупателей условий в целях возмещения затрат, связанных с приобретением товаров предприятий, деятельность которых локализована на территории соответствующего государства. Например, в обращении о проведении консультаций по субсидиям, подготовленном ЕС по поводу мер, применяемых Турцией в отношении производства, импорта и маркетинга фармацевтической продукции, обозначена проблема, связанная с ограничением Турцией конкурентоспособности иностранных производителей товаров путем исключения импортного продукта из схемы возмещения затрат покупателей'.

Кроме того, субсидией для целей ВТО может выступать более низкий уровень фискальной нагрузки, применяемый в отношении резидентов государства, установившего соответствующий фискальный режим, по сравнению с иностранными производителями конкурирующих товаров. Например, проблемы в рамках ВТО вызвал введенный на территории России с 1 сентября 2012 года утилизационный сбор, являющийся по своей природе альтернативным механизмом по отношению к прямым импортным пошлинам на транспортные средства иностранного производства². В результате положения Федерального закона от 24.06.1998 № 89-Ф3 «Об отходах производства и потребления» были подвергнуты корректировке в целях определения

\footnotetext{
${ }^{1}$ Turkey - certain measures concerning the production, importation and marketing of pharmaceutical products request for consultations by the European Union. 10 April 2019. - URL: https://docs.wto.org/dol2fe/Pages/FE_Search/FE_S_S006. aspx?Query=(\%20@Symbol=\%20g/scm/d*\%20)\&Language=ENGLISH\&Context=FomerScriptedSearch\&languageUIChanged =true\#

${ }^{2}$ Russian Federation - Recycling Fee on Motor Vehicles. - URL: https://www.wto.org/english/tratop_e/dispu_e/cases_e/ ds463_e.htm
} 
одинакового уровня фискальной нагрузки для производителей транспортных средств - как имеющих статус резидента ЕАЭС, так и не имеющих такового.

Международные правила о порядке субсидирования приводят к ограничениям в части применения механизма финансирования, что негативно сказывается на развитии определенных сегментов экономики государства. Например, согласно Приложению II к Протоколу от 16.12.2011 «О присоединении Российской Федерации к Марракешскому соглашению об учреждении Всемирной торговой организации от 15 апреля 1994 года» внутренняя поддержка государства по сельскому хозяйству ограничена фиксированной денежной суммой, которая поэтапно подлежит уменьшению.

Для целей применения Договора о Евразийском экономическом союзе термин «субсидия» используется в следующих значениях: а) финансовое содействие, которое оказывается субсидирующим органом (или уполномоченной государством-членом структурой), в результате которого создаются (обеспечиваются) преимущества и которое осуществляется посредством прямого перевода денежных средств, полного или частичного отказа от взимания платежей, которые должны были бы поступать в доход государства (например, налоговые льготы, списание долга); б) любая другая форма поддержки доходов или цен, которая действует (прямо или косвенно) на сокращение ввоза промышленного товара с территории любого государства-члена или на увеличение вывоза промышленного товара на территорию любого государства-члена, в результате чего предоставляется преимущество.

В сложившейся ситуации государству приходится применять альтернативные способы государственной поддержки отечественных производителей. В частности, в Российской Федерации универсальная субсидия компаниям под обязательства по экспорту заменяется займами, предоставляемыми Фондом развития промышленности. Однако следует учитывать, что споры о соответствии субсидии правилам ВТО может вызывать и процедура предоставления займов с процентными ставками ниже рыночных, а также покупка конвертируемых облигаций на более выгодных, по сравнению с рыночными, условиях

Изложенные критерии предоставления субсидий, выработанные в международной практике, необходимо учитывать в целях совершенствования национального законодательства о субсидировании, которое пока имеет ряд серьезных недостатков.

Проблемы предоставления финансовой помощи в форме субсидий связаны с тем, что правоприменители ошибочно относят субсидию к гражданскоправовой сфере регулирования, а споры о порядке исполнения соглашений о предоставлении субсидий разрешают в соответствии с нормами гражданского законодательства о денежных обязательствах гражданско-правовой природы, имеющих эквивалентно-возмездный характер. В частности, Верховный Суд РФ неоднократно указывал, что правоотношения между органом,

\footnotetext{
${ }^{3}$ Korea - measures affecting trade in commercial vessels (second complaint) (Japan) request for consultations by Japan 10 February 2020. - URL : https://docs.wto.org/dol2fe/Pages/FE_Search/FE_S_S006.aspx?Query=(\%20@Symbol=\%20g/ $\left.\mathrm{scm} / \mathrm{d}^{\star} \% 20\right) \&$ Language=ENGLISH\&Context=FomerScriptedSearch\&languageUIChanged=true\#
} 
предоставляющим субсидию, и лицом, претендующим на ее получение (производителем товаров, работ, услуг), несмотря на то, что в большей степени регулируются нормами БК РФ, не являются бюджетными правоотношениями. Следовательно, к отношениям сторон по исполнению условий договора о предоставлении субсидии могут быть применены нормы ГК РФ (определения Судебной коллегии по экономическим спорам Верховного Суда РФ От 19.01.2018 № 308-ЭС17-9296 по делу № А32-41306/2016; от 28.02.2018 № 304-ЭС17-23700 по делу № А27-4106/2017).

Полагаем, что выработанный в судебной практике подход является спорным, поскольку предоставление субсидий не ограничено удовлетворением частноправовых интересов, а, как отмечает Конституционный Суд РФ в постановлении от 16.07.2018 № 32-П, направлено на достижение законодательно обусловленных задач субсидирования публично значимой предпринимательской деятельности организаций.

Субсидия как инструмент экономического регулирования представляет собой предусмотренную БК РФ форму финансирования, основанную на формировании и исполнении финансовых обязательств расходного типа, которые, в отличие от гражданских обязательств, не нацелены на встречное удовлетворение. Сам по себе факт применения конструкции соглашения в регулировании бюджетных субсидий не может рассматриваться в качестве аргумента, свидетельствующего о принадлежности данного типа денежных обязательств к гражданско-правовой сфере. Это связано с тем, что финансовое законодательство не существует изолированно от иных отраслей законодательства, поэтому при регулировании финансовых отношений могут применяться межотраслевые юридические конструкции, имеющие универсальный характер, которые по общему правилу признаются актами гражданского законодательства.

В рассматриваемых случаях соглашения, в рамках которых определены условия предоставления субсидии хозяйствующим субъектам, являются способом формирования отношений, складывающихся в сфере финансирования и урегулированных бюджетно-правовыми средствами. При всей схожести регулирования отношений посредством соглашения с гражданско-правовой моделью договора следует принимать во внимание, что орган отраслевого управления, предоставляя субсидию, реализует не свой имущественный интерес, а интерес публичный, связанный с потребностями всей экономики страны, а получатель субсидии не становится должником, то есть для признания отношений субсидии гражданско-правовым договором не хватает самого главного - встречного удовлетворения.

Бросается в глаза и то, что субсидирование хозяйствующих субъектов в целом не подчиняется гражданскому законодательству, а подпадает под действие отраслевых актов, определяющих категории, критерии отбора, цели, условия и порядок предоставления субсидий, существенно различных между собой. Напрашивается вывод о том, что субсидии в современных условиях в какой-то мере предоставляют министерствам и ведомствам возможность напрямую финансировать те или иные мероприятия подведомственных 
предприятий и таким образом восполняют утраченные возможности административного принуждения в сфере технической и экономической политики.

В настоящее время в российском правовом поле отсутствуют четкие параметры отграничения субсидий, в том числе грантов, от иных, смежных с ними инструментов финансирования. В зарубежном законодательстве, напротив, критерии отграничения форм финансирования имеют четкое закрепление. Например, принятый в 1978 году закон США «О субсидиях и соглашениях о сотрудничестве» был призван служить руководством для государственных учреждений в использовании ими бюджетных средств, в частности, путем определения роли государственных контрактов и субсидий. Согласно указанному закону государственная закупка как правовой инструмент применяется в том случае, когда финансирование проекта направлено на извлечение прямой выгоды для федерального правительства. В свою очередь, использование соглашений о субсидиях (грантовых соглашений) направлено на оказание финансовой поддержки в целях стимулирования деятельности участников гражданского оборота, направленной на реализацию публичного интереса 4 . И наконец, использование концессионных соглашений направлено на распределение финансовой нагрузки при реализации инвестиционных проектов на основе принципа стыковки частных и публичных интересов в целях «...передачи ответственности за реализацию проекта субъекту частного сектора» 5 .

Не разрешенная пока в российском законодательстве и правоприменительной практике проблема разграничения форм финансирования инвестиционных проектов приводит к скрытым финансовым рискам для бюджетной системы. Сложившийся в государстве порядок предоставления финансовой помощи в форме субсидий зачастую представляет собой механизм выведения государственного финансирования за рамки правового режима, установленного Бюджетным кодексом РФ и Федеральным законом от 05.04.2013 № 44-Ф3 «О контрактной системе в сфере закупок товаров, работ, услуг для обеспечения государственных и муниципальных нужд», являющимся инструментом оценки эффективности использования бюджетных средств на стадии заключения государственного (муниципального) контракта, а действующий порядок финансирования инвестиционных проектов в форме концессионных соглашений с учетом применяемых условий и объемов бюджетного финансирования по своей природе является государственной закупкой.

Во многом это связано с тем, что в правоприменительной практике сформирован подход, исключающий ограничения по размеру платы концедента. Суды исходят из того, что наряду с финансированием инвестиционного проекта в форме капитального гранта законодательство о концессиях не исключает возможность возмещать оставшуюся часть расходов концессионера за счет

\footnotetext{
${ }^{4}$ Public Law 95-224. - FEB. 3, 197892 STAT. 3, 95th Congress. An Act To distinguish Federal grant and cooperative agreement relationships from Federal procurement relationships, and for other purposes. - URL: https://www.govinfo.gov/ content/pkg/STATUTE-92/pdf/STATUTE-92-Pg3.pdf

${ }^{5}$ Expanding the market for infrastructure public-private partnership: alternative risk and profit sharingapproaches to align sponsor and investor interests. U.S. Department of the Treasure // Office of Economic Policy April 2015. - URL: https://www. treasury.gov/connect/blog/Documents/Treasury\%20Infrastructure\%20White\%20Paper\%20042215.pdf
} 
платы концедента. Такой подход, например, изложен в постановлении Девятого арбитражного апелляционного суда от 04.09.2017 по делу № A40-23141/17.

Существуют примеры и обратной трансформации, когда, исходя из объема прав инвестора на созданное в рамках проекта имущество, производят переквалификацию государственных закупок в концессии. Так, ФАС Уральского округа в постановлении от 06.07.2011 № Ф09-3353/11 признал условия государственного контракта недействительными и не соответствующими положениям Федерального закона от 21.07.2005 № 115-Ф3 «О концессионных соглашениях» на том основании, что условия контракта предусматривают возникновение права собственности подрядчика на построенные им за счет собственных средств объекты.

Таким образом, в современных условиях в правоприменительной практике происходит подмена форм финансирования инвестиционных проектов, что ограничивает вливание в экономику частных инвестиций, приводит к скрытым финансовым рискам для государства и, наконец, подрывает принцип эффективности использования бюджетных средств [1].

Вместе с тем государственные закупки, концессионные соглашения, а также соглашения о предоставлении субсидий (грантов) являются самостоятельными, существенно различающимися между собой правовыми инструментами, обеспечивающими тот или иной тип взаимодействия между государством и участниками гражданского оборота в рамках финансовых правоотношений. Следовательно, порядок взаимодействия между указанными субъектами обеспечивает создание соответствующих форм финансирования, различающихся по объему и характеру прав и обязанностей участников финансовых правоотношений в части реализации процедуры предоставления и использования бюджетных средств, а также осуществления полномочий по поводу владения, пользования и распоряжения имуществом, созданным с привлечением бюджетных средств.

Отметим и то, что сложившийся подход к правовому регулированию субсидий не способствует созданию единого порядка применения мер имущественной ответственности к организациям и индивидуальным предпринимателям за нарушение условий соглашений о предоставлении субсидий, что не позволяет обеспечить стабильность и недвусмысленность регулирования финансовых отношений. Вызывают сомнения в правомерности ситуации случаи, когда за нарушение условий соглашения о предоставлении субсидий органами отраслевого финансирования с предприятий взыскиваются проценты за пользование чужими денежными средствами в порядке, предусмотренном ст. 395 ГК РФ. Отмеченный подход, по нашему мнению, противоречит правовой природе субсидии и сводит на нет ее созидательный потенциал, направленный на реализацию национальных проектов и государственных программам по развитию отраслей российской экономики.

Анализ подзаконных нормативных правовых актов, закрепляющих порядок предоставления субсидий, демонстрирует неоднозначный подход законодателя к определению объема бюджетных средств, подлежащих возврату в случае нарушения условий предоставления субсидий или недостижения 
показателей результативности. Такой подход ставит участников гражданского оборота в неравные условия осуществления хозяйственной деятельности, что является нарушением конституционных принципов равенства всех перед законом, соразмерности имущественной ответственности совершенному правонарушению и в конечном счете не позволяет обеспечить стабильность регуляторного режима в бюджетной сфере.

Являясь инструментом государственного финансирования, субсидии, по нашему мнению, охватываются закрепленными БК РФ критериями оценки эффективности и целевого использования бюджетных средств, поэтому установленные органами исполнительной власти критерии результативности использования субсидий должны применяться с учетом общих положений о целевом и эффективном расходовании бюджетных средств, закрепленных В СТ. 38, 306 $и$ и 34 БК РФ.

Иными словами, оценка соблюдения условий предоставления субсидий должна осуществляться через призму реализации принципов целевого и эффективного использования бюджетных средств. При этом возврат необоснованно использованных субсидий обеспечивается межотраслевой юридической конструкцией возмещения ущерба, порядок применения которой определен в ст. $270^{2}$ БК РФ. Согласно этой статье в случае установления факта нарушения нормативных правовых актов, регулирующих бюджетные правоотношения, органами государственного (муниципального) финансового контроля составляется предписание с требованием о возмещении причиненного ущерба публично-правовому образованию.

Учитывая, что понятие ущерба в БК РФ не закреплено, наличие причиненного публично-правовому образованию ущерба допустимо определять по критериям, аналогичным указанным в п. 2 ст. 15 ГК РФ, позволяющим применить имущественную ответственность в размере, соответствующем совершенному правонарушению. Обозначенный подход изложен в письме Министерства финансов РФ от 04.08.2015 № 02-10-09/45065 «О разъяснении отдельных положений Бюджетного кодекса, Кодекса об административных правонарушениях и других законодательных актов РФ».

Таким образом, объем взыскиваемых с получателя субсидии бюджетных средств в случае нарушения условий их получения, а также нарушения критериев результативности и целевого характера использования определяется с учетом исполненного объема обязательства в соответствии с условиями предоставления субсидий.

На наш взгляд, предоставление субсидий осложняется применением многоступенчатого механизма финансирования. Помимо отраслевого финансирования через министерства и ведомства к процедуре предоставления субсидий все более активно привлекаются специально созданные фонды, цель которых состоит в софинансировании расходов участников научно-технических или экономических программ.

Текущий период развития бюджетного устройства идет во многом под знаком создания специализированных фондов, призванных к субсидированию 
особых экономических субъектов, вовлеченных в наиболее перспективные или проблемные социальные сферы. Упомянем Фонд развития моногородов, Фонд содействия реформированию жилищно-коммунального хозяйства, Российский фонд фундаментальных научных исследований, Фонд содействия развитию малых форм предприятий в научно-технической сфере и т.д. Для деятельности этих организаций характерно, прежде всего, то, что предоставляемые ими субсидии выдаются в форме грантов. Потенциал, заложенный в грантовом финансировании, неоспорим: далеко не случайно он используется во все большем числе отраслей и сфер экономики.

Отметим, что грант и субсидия практически синонимы. Большая часть положений, относящихся к субсидиям по БК РФ, вполне применима и к грантам. В БК РФ предусмотрено два вида субсидий, обладающих абсолютно разной сущностью и регламентацией: «межбюджетные» субсидии, представляющие собой форму межбюджетных трансфертов и выделяемые бюджетам другого уровня, и «бюджетные» субсидии, предоставляемые физическим и юридическим лицам. Как уже было установлено, грант - это форма бюджетной субсидии, а значит, на него распространяются соответствующие нормы законодательства о бюджетных субсидиях. Между тем БК РФ содержит довольно скудное регулирование оборота бюджетных субсидий, в основном сосредоточенное в ст. 78 и 781, а также в некоторых других.

К сожалению, названные статьи содержат крайне мало общих норм, применимых ко всем бюджетным субсидиям, в том числе грантам. Почти каждый пункт данных статей касается разных видов бюджетных субсидий и носит характер специальных (а не общих) норм. Например, пп. 1-3 ст. 78 определяют правовой режим субсидий производителям товаров, работ, услуг в целях возмещения недополученных доходов; п. 4 - правовой режим субсидий лицам на возмещение затрат по уплате таможенных платежей; п. 7 - субсидий в форме грантов; пп. 8-84 - субсидий на осуществление капитальных вложений и т.д.

Согласно Общим требованиям к нормативным правовым актам и муниципальным правовым актам, устанавливающим порядок предоставления грантов в форме субсидий, в том числе предоставляемых на конкурсной основе, утвержденным постановлением Правительства РФ от 27.03.2019 № 322 (далее - Общие требования), установление требований, в соответствии с которыми предоставляются гранты, отнесено к полномочиям органа, утверждающего конкретные положения о грантах. Это касается таких важных моментов, как порядок расчета грантов, сроки подачи и рассмотрения заявок, порядок отбора получателей, порядок финансирования (авансирование либо платежи по факту выполнения), порядок и формы отчетности и многие другие. Кроме того, постановление устанавливает общие требования лишь к нормативным правовым актам о предоставлении грантов, а не к самой грантовой деятельности и к порядку бюджетного финансирования.

Нивелирует значимость рассматриваемого документа и то обстоятельство, что закрепленные в нем требования не распространяются на предоставление грантов в форме субсидий в порядке, предусмотренном абз. 1 п. 7 ст. 78 
и абз. 1 п. 4 ст. 78¹ БК РФ. Иначе говоря, если правила предоставления отдельных видов грантов установлены в конкретных решениях о предоставлении этих грантов, данные правила имеют приоритет перед общими требованиями, установленными в постановлении Правительства РФ № 322. Соответственно постановление применяется по «остаточному» принципу. Это свидетельствует о том, что осуществляется локальное узконаправленное правовое регулирование под каждый грант, однако никаких общих требований к грантовому финансированию не существует.

Тем не менее несколько важных дополнений о грантах постановление Правительства РФ № 322 все-таки содержит. В нем, в частности, установлен запрет на двойное финансирование одной и той же деятельности. В п. 4 Общих требований сказано, что «участник отбора не получает в текущем финансовом году или на дату, определенную правовым актом, средства из бюджета, из которого планируется предоставление гранта, в соответствии с иными правовыми актами на цели, установленные правовым актом». В Общих требованиях также указано, что «участник отбора, являющийся юридическим лицом, на дату, определенную правовым актом, не должен находиться в процессе ликвидации, банкротства, а участник отбора, являющийся индивидуальным предпринимателем, не должен прекратить деятельность в качестве индивидуального предпринимателя».

Заслуживает внимания п. 5 Общих требований, где сформулировано спорное положение о том, что дополнительным требованием к участнику оборота, являющемуся бюджетным или автономным учреждением, является условие о предоставлении согласия органа, осуществляющего функции и полномочия учредителя в отношении этого учреждения, на участие в отборе, оформленного на бланке указанного органа.

Таким образом, отождествление гранта с субсидией создает терминологическую неопределенность в БК РФ и приводит К возникновению разных процедур предоставления грантовой формы финансирования, проблемы эффективности реализации которых требуют изучения.

Законодательством РФ предусмотрены следующие процедуры предоставления грантов: 1) предоставление грантов в рамках отраслевого финансирования через процедуру конкурсного отбора; 2) предоставление грантов через специально созданные организации (фонды, являющиеся проводниками бюджетных денег до грантополучателей) [2].

Предоставление грантов в рамках отраслевого финансирования через процедуру конкурсного отбора осуществляется в пределах лимитов бюджетных обязательств, доведенных до главных распорядителей бюджетных средств. В рассматриваемом случае гранты предоставляются в форме субсидий субъектам предпринимательской деятельности в соответствии со ст. 78 БК РФ. Порядок предоставления грантов бюджетным и автономным учреждениям регламентируется ст. $78^{1}$ БК РФ. На основании указанной статьи бюджетные ассигнования на предоставление грантов в форме субсидий выделяются бюджетным и автономным учреждениям по результатам конкурсного отбора. 
Анализ сложившегося порядка предоставления финансовой помощи в форме грантов позволяет сделать вывод о том, что меры грантовой формы финансирования, реализуемые во всех сегментах экономики, несистемны и малоэффективны. На основании отчета Счетной палаты РФ, подготовленного по итогам анализа реализации мер государственной поддержки молодых российских ученых в 2016-2018 годах, грантовое финансирование не нацелено на конечный результат, а именно на экономический эффект. Так, меры по поддержке малого предпринимательства в сельском хозяйстве, реализуемые в рамках Госпрограммы и региональных программ развития агропромышленного комплекса, широкого распространения не получили и не оказали существенного влияния на развитие малых форм хозяйствования на селе.

Изложенное подводит к вопросу о том, насколько сформированный в государстве подход к предоставлению субсидий через специализированные фонды является эффективным.

Очевидно, что создание «проводников» бюджетных денег в виде специализированных фондов влечет дополнительные бюджетные расходы, что не всегда оправданно. Это можно проиллюстрировать на примере отчета Счетной палаты РФ, подготовленного по результатам анализа деятельности Фонда развития моногородов. Контрольным ведомством выявлен ряд существенных недостатков в работе Фонда, ключевое значение среди которых отводится чрезмерно высоким затратам Фонда на выплаты персоналуб.

Отмеченные Счетной палатой РФ недостатки объясняются тем, что наличие посредников при осуществлении операций с бюджетными средствами приводит к коммерциализации механизма предоставления субсидий, а также к неэффективному их использованию [3].

Приведенные органом финансового контроля выводы имеют важное значение в рамках проведения правовой оценки эффективности создания многочисленных специальных фондов грантового финансирования, которые в современных условиях получили активное развитие. В результате финансирование отдельных сегментов, например научно-исследовательской сферы, осуществляется одновременно через различные механизмы предоставления финансовой помощи, что затрудняет возможность достоверно оценить общий объем средств бюджета с учетом расходов на обеспечение государственного задания, направленного участникам гражданского оборота.

Полагаем, что на законодательном уровне целесообразно четко определить критерии, при наличии которых финансовая помощь в форме грантов может предоставляться через специализированные фонды, конкурирующие с механизмом отраслевого финансирования. При определении обозначенных критериев следует учитывать принципы осуществления финансовых обязательств, обеспечивающие реализацию предусмотренных бюджетным законодательством

\footnotetext{
${ }^{6}$ Агапцов А. А., Шторгин С.И. Отчет о результатах экспертно-аналитического мероприятия «Мониторинг и оценка хода реализации приоритетной программы «Комплексное развитие моногородов» / Утвержден коллегией Счетной палаты Российской Федерации 26 марта 2019 года // Бюллетень Счетной палаты Российской Федерации. 2019. № 7 (259). URL: www.ach.gov.ru20.
} 
форм финансирования. Поскольку при возникновении и исполнении финансовых обязательств главным выступает принцип сближения частных и публичных интересов, предполагаем, что создание специализированных фондов грантового финансирования будет эффективным механизмом финансовой поддержки лишь в случае заинтересованности частных субъектов в формировании этих фондов. Иными словами, фонд предоставления финансовой помощи должен выступать механизмом стыковки частных интересов и общих целей и создаваться преимущественно за счет денежных средств, мобилизация которых может происходить в любых допустимых законодательством формах.

Подтверждением приведенного вывода выступает сложившийся в США положительный опыт по созданию специализированного фонда финансирования грантовых программ, направленных на защиту окружающей среды. Например, в соответствии с законом США от 06.07.2012 «Об устойчивости ресурсов и экосистем, туристических возможностях и возрожденных экономиках государств

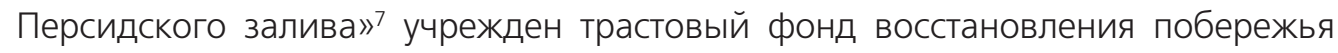
Мексиканского залива, в который поступает 80 процентов гражданских штрафов, выплаченных после 6 июля 2012 года в соответствии с Федеральным законом США «О борьбе с загрязнением воды в связи с разливом нефти». Согласно этому закону средства целевого фонда выделяются на программы, проекты и мероприятия, направленные на восстановление и защиту окружающей среды и экономики региона побережья Мексиканского залива, в том числе на реализацию двух грантовых программ, находящихся в ведении казначейства.

Тенденция на создание грантовой формы финансирования на основе принципа стыковки частных интересов и общих целей прослеживается и в Российской Федерации. Например, задачей реализации национального проекта «Наука» является создание не менее 15 научно-образовательных центров мирового уровня на основе интеграции университетов и научных организаций и их кооперации с организациями, действующими в реальном секторе экономикив. Осуществление указанного национального проекта нацелено на привлечение внебюджетных источников финансирования научно-исследовательской деятельности.

Представляется, что следовало бы разграничить промышленные субсидии как меру экономической и технической поддержки государственных, муниципальных и частных товаропроизводителей с регламентацией этих субсидий в БК РФ и субсидии-гранты, предоставляемые на научные, научно-технологические и внедренческие цели, законодательной основой которых мог бы стать специальный закон о грантовой поддержке науки и научных исследований.

Проведенное исследование позволяет сформулировать ряд следующих выводов.

1. Субсидия представляет собой предусмотренную БК РФ форму финансирования, основанную на формировании и исполнении финансовых обязательств

\footnotetext{
${ }^{7}$ Public Law 112-141-July 6, 2012. - URL: https://www.govinfo.gov/content/pkg/PLAW-112publ141/pdf/PLAW112publ141.pdf

8 Паспорт национального проекта «Наука» (утвержден президиумом Совета при Президенте РФ по стратегическому развитию и национальным проектам, протокол от 24.12.2018 № 16).
} 
расходного типа, которые, в отличие от гражданских обязательств, не нацелены на встречное удовлетворение. Сам по себе факт применения конструкции соглашения в регулировании бюджетных субсидий не может рассматриваться в качестве доказательства, свидетельствующего о принадлежности данного типа денежных обязательств к гражданско-правовой сфере. Скорее это соглашение следует признать административным договором. Соответственно ключевое значение в механизме правового регулирования бюджетных субсидий имеют нормы финансового законодательства об оценке законности и обоснованности целевого выделения и использования бюджетных средств.

2. Ненадлежащее выполнение условий соглашений о предоставлении субсидий представляет собой нарушение закрепленных БК РФ принципов целевого и эффективного использования бюджетных средств, критерии применения которых должны учитываться органами финансового контроля в совокупности с критериями результативности, установленными в отношении каждой формы финансирования по соответствующей отрасли и вида выполняемых работ, оказываемых услуг. Применение мер имущественной ответственности к получателям субсидий не должно выходить из сферы действия положений БК РФ. В частности, взыскание необоснованно использованных бюджетных средств должно осуществляться путем применения конструкции возмещения ущерба, причиненного бюджетной системе, размер которого в силу неурегулированности этого вопроса БК РФ определяется в порядке, аналогичном установленному ст. 15 ГК РФ, что позволяет взыскать в доход бюджета субсидию в пропорции с ущербом от установленного нарушения.

3. Механизм применения мер имущественной ответственности за нарушение финансовых обязательств, к которым, в частности, относятся обязательства в сфере предоставления бюджетной субсидии субъектам предпринимательской деятельности, закреплен в БК РФ. При этом нормы и конструкции гражданского, административного и иных отраслей законодательства не обладают приоритетом перед бюджетным законодательством и могут применяться при регулировании финансовых отношений либо в силу прямого указания финансового закона, либо в силу отсутствия в актах финансового законодательства специального регулирования, то есть по принципу аналогии права или аналогии закона.

4. Оценивая сформированный в законодательстве механизм предоставления грантов, следует исходить из критериев, при наличии которых финансирование в форме грантов может предоставляться через специально созданные фонды на цели, не предполагающие отраслевого финансирования.

Поскольку при возникновении и исполнении финансовых обязательств ключевым выступает принцип сближения частных и публичных интересов, создание специализированных фондов будет эффективным механизмом предоставления грантов лишь в случае заинтересованности в их формировании частных субъектов (физических лиц и организаций). Иными словами, соответствующий фонд предоставления финансовой помощи в форме грантов должен выступать механизмом стыковки частных интересов и общих целей и формироваться преимущественно за счет средств частных инвесторов. 
В складывающихся экономических условиях резко повышается роль государственного финансирования затрат хозяйственных организаций, научно-исследовательских учреждений, индивидуальных предпринимателей на цели, предполагающие определенный публичный интерес, - реализацию результатов НИР, инвестиции в перспективные производства, «расшивку узких мест» для развития экономики.

5. Получение бюджетной системой новых функций остро ставит вопросы правового совершенствования осуществления бюджетных расходов. Привычное сметно-бюджетное финансирование заменяется новыми инструментами - субсидиями, субвенциями, грантами, но в юридическом отношении эта замена несколько отстает от потребностей практики и создает ряд проблем, требующих решения в целях формирования современного механизма осуществления государственных (публичных) расходов и его увязки с режимом самофинансирования хозяйствующих субъектов, включая некоммерческие организации. В этом направлении должны быть преодолены реликты безвозвратного финансирования из бюджета, равно как и поверхностной отчетности о произведенных расходах и достигнутых результатах.

6. Субсидии, субвенции, гранты выступают как юридические средства обеспечения двусторонности бюджетных взаимоотношений, привнесения ответственности в эти отношения за использование бюджетных средств, а главное достижения экономического эффекта как для субъекта-исполнителя, так и для всего общества. Законодателем предпринимаются энергичные попытки по развитию и углублению субсидирования как главного способа осуществления инвестиций и оказания хозяйствующим субъектам экономической поддержки.

С. В. ЗАПОЛЬСКИЙ, главный научный сотрудник сектора административного права и административного процесса Института государства и права РАН, доктор юридических наук, профессор

Е. Л. ВАСЯНИНА, ведущий научный сотрудник сектора финансового, налогового, банковского и конкурентного права Института государства и права РАН, доктор юридических наук, доцент

\section{Библиографический список}

1. Васянина Е. Л. Юридическая техника формирования и исполнения доходно-расходных финансовых обязательств // Налоги и финансовое право. 2020. № 4. С. 151-158.

2. Запольский С. В., Васянина Е. Л. Информационно-правовое обеспечение организации научных исследований на основе государственной грантовой поддержки // Правовая информатика. 2019. № 3. С. 50-53.

3. Васянина Е. Л. Обязательства в финансовом праве: монография. - М.: Русайнс, 2020. 